\title{
Pobreza multidimensional em Santa Catarina (2000-2010): uma aplicação do método Alkire-Foster
}

\author{
Multidimentional poverty in Santa Catarina (2000-2010): an application of the alkire-foster \\ method
}

Mayara da Mata Moraes ${ }^{\mathrm{I}}$, Solange Regina Marin ${ }^{\mathrm{II}}$ e Carine de Almeida Vieira ${ }^{\mathrm{II}}$

\begin{abstract}
Resumo
Com o decorrer dos anos, o conceito de pobreza evoluiu da perspectiva da subsistência - que relaciona pobreza com o mínimo necessário para sobrevivência - para as necessidades básicas - que promove questões vinculadas ao atendimento de serviços como educação e saúde e para a concepção da privação relativa - que incorporou o contexto socioeconômico e o padrão de vida da sociedade em questão. Na concepção da abordagem das capacitações, que entende a privação como falta de realização de determinados funcionamentos e capacitações, entende-se pobreza como um fenômeno multidimensional. Da mesma forma, os métodos de medição de pobreza também evoluíram das linhas de pobreza para medidas como: headcount index, poverty gap index, squared poverty gap index e Sen index, Índice de Desenvolvimento Humano (IDH), Índice de Pobreza Humana (IPH) e Índice de Pobreza Multidimensional (IPM) que é baseado no método Alkire-Foster (2009). O objetivo desse estudo é aplicar o método Alkire-Foster (2009) para os municípios de Santa Catarina nos anos de 2000 e 2010. Alguns resultados revelam que a pobreza multidimensional tem diminuído no estado: a incidência de pobreza multidimensional diminuiu de 26,66\% em 2000 para 15,07\% em 2010.
\end{abstract}

Palavras-chave: Pobreza uni e multidimensional; Medidas de pobreza,; Método Alkire-Foster

\begin{abstract}
Over the years, the concept of poverty has evolved from a subsistence perspective - linking poverty with the minimum necessary for survival - to basic needs - that promotes issues related to the provision of services such as education and health and to the conception of relative deprivation - which incorporated the socioeconomic context and the standard of living of the society in question. Through the capabilities approach, which understands deprivation as a lack of achievement of certain functioning and capabilities, poverty is understood as multidimensional phenomena. Likewise, poverty measurement methods have also evolved from poverty lines to measures such as: headcount index, poverty gap index, squared poverty gap index, Sen Index, Human Development Index (HDI), Human Poverty Index (HPI) and Multidimensional Poverty Index (MPI), which is based on the Alkire-Foster method (2009). This paper aims to apply the Alkire-Foster method (2009) to the cities of Santa Catarina in 2000 and 2010. Some results show that multidimensional poverty has declined in the state: the incidence of multidimensional poverty decreased from $26.66 \%$ in 2000 to $15.07 \%$ in 2010 .
\end{abstract}

Keywords: Uni and multidimensional poverty, poverty measures, Alkire-Foster method 


\section{Introdução}

Existem diferentes concepções de pobreza e diversas metodologias de cálculo, no entanto não há um consenso sobre qual método é o mais adequado. A maior parte das medidas de pobreza usadas tem como embasamento teórico as abordagens unidimensionais levando em consideração somente a variável renda monetária que ignora indicadores de bem-estar tais como níveis educacionais, níveis de saúde e de saneamento básico e condições de moradia.

As várias tentativas de mensuração da pobreza percorre o caminho de formas unidimensionais que possuem a renda como variável focal às formas multidimensionais. Os relatórios de desenvolvimento humano mostram tal evolução e apresentam as várias medidas desde as tradicionais baseadas na definição de linha de pobreza, que também podem ser encontradas em publicações do Banco Mundial (2005), até as medidas multidimensionais que abarcam um número mais amplo de variáveis e dimensões.

Os métodos de pobreza de caráter unidimensional trazem a lógica dual de identificação de pobres e não pobres, identificação esta que é baseada somente na renda monetária. Medidas como a proporção dos pobres, hiato médio de pobreza e hiato quadrático de pobreza são interpretadas a partir dos valores verdade 0 e 1 em que 0 significa inexistência de pobres e 1 que toda a população é pobre. Essas medidas podem ser contrastadas com medidas de caráter multidimensional como Índice de Desenvolvimento Humano (IDH), apresentado pelo Relatório de Desenvolvimento Humano (RDH) de 1990, que entende desenvolvimento a partir da expansão das escolhas das pessoas e, portanto, para além da renda, inclui variáveis como saúde, educação e padrões de vida.

O aperfeiçoamento desses métodos continua passando pelo Índice de Pobreza Humana (IPH) exposto pela primeira vez no RDH (1997) e chegando até a última proposta de uma medida multidimensional o Índice de Pobreza Multidimensional (IPM) apresentada no RDH (2010) e que tem por base o trabalho de Alkire \& Foster (2009). Dotter \& Klasen (2014) argumentam que uma das principais vantagens do IPM é que ele é suficientemente simples para realizar comparações internacionais e assim rivalizar com a linha de pobreza. O IPM já foi calculado para mais de 100 países em desenvolvimento, é flexível em relação a sua base de dados (com a possibilidade de combinação de dados cardinais, ordinais e categorias) e pode ser desagregado por grupos, regiões e dimensões.

A questão que permeia o trabalho é a seguinte: é possível identificar, com base em uma análise multidimensional, os municípios mais e menos pobres multidimensionalmente em Santa Catarina e se houve mudança na condição de pobreza no período de 2000 a $2010 ?$

Além da introdução, o artigo está dividido em mais cinco partes. Na seção subsequente, é apresentada a evolução do conceito de pobreza a partir das suas diferentes perspectivas. Na seção posterior, são tratadas as medidas de pobreza unidimensionais e as linhas de pobreza e na parte seguinte é discutida a respeito das medidas de pobreza multidimensionais que possuem um foco multifacetado. A parte seguinte descreve o estado catarinense via Índice de Desenvolvimento Humano Municipal (IDHM) e outros dados referentes à população e ao bem-estar. A próxima seção trata de uma revisão de diferentes trabalhos publicados no Brasil sobre pobreza multidimensional e suas formas de medidas, seguindo da aplicação do método Alkire-Foster (2009) para Santa Catarina nos anos de 2000 e 2010. A seção final apresenta algumas considerações.

\section{Evolução do conceito e medidas de pobreza}

\subsection{O conceito de pobreza}

$\mathrm{Na}$ atualidade, pobreza é a privação de algo e engloba questões tanto econômicas quanto sociais. Rocha (2006) enfatiza que é imprescindível a clara compreensão de quais são essas necessidades e qual é o nível de atendimento que é aceitável dentro de certo contexto socioeconômico.

A pobreza unidimensional ou pobreza absoluta pode ser entendida segundo a perspectiva da subsistência, a primeira corrente de pensamento sobre a pobreza. O debate se iniciou pela forma como os pobres eram tratados via Lei dos Pobres1, leis que especificavam determinada quantidade de pão de acordo com o atendimento das necessidades físicas. Nos anos 1890, trabalhos e pesquisas de profissionais da nutrição também influenciaram a concepção de subsistência. Após a Segunda Guerra Mundial, a ideia de subsistência, segundo Codes (2008, p.11), agregou a noção de pleno emprego defendida por Sir William Beveridge, trazendo alguns aspectos sociais para o debate e imputando ao Estado a obrigação de proporcionar a todos os cidadãos da Grã-Bretanha uma alocação empregatícia.

Essa perspectiva unidimensional é alvo de inúmeras críticas segundo Townsend (1993 apud Codes, 2008) que se referem

${ }^{1}$ A Lei dos Pobres (Poor Law) foi desenvolvida na Inglaterra por volta de 1536 e reformulada (Poor Law Reform) em 1834 substituindo a Speenhamland Law de 1795. A Lei dos Pobres era, segundo Pereira (2000, p.103), "um conjunto de regulações pré-capitalistas que se aplicava às pessoas situadas à margem do trabalho, como idosos, inválidos, órfãos, crianças carentes, desocupados voluntários e involuntários, etc.". Nesse sentido, apenas os pobres incapacitados tinham direito à assistência social, os pobres que não eram inválidos eram obrigados a aceitar qualquer tipo de trabalho, visto que a mendicância castigada. 
à estreiteza com que a pobreza é entendida, isto é, engloba somente a noção de necessidades físicas a serem atendidas e a inclusão dos cidadãos, principalmente aqueles de pouco produtividade, no mercado de trabalho, e coloca como critério chave para erradicar o problema a renda. Isso faz com que questões tão pertinentes para a formação do ser humano como serviços de educação e saúde e direitos de cidadania não sejam interpeladas nessa perspectiva.

Essa perspectiva está ligada à compreensão de pobreza absoluta, que se define como o mínimo necessário para a sobrevivência. Rocha (2006, p.11) entende a pobreza absoluta como "questões de sobrevivência física" que não são alcançadas e ao "não atendimento das necessidades vinculadas ao mínimo vital”. Segundo Crespo e Gurovitz (2002, p.4), essa perspectiva, que predominou até a década de 1950, foi usada pelo Banco Internacional para a Reconstrução e o Desenvolvimento (BIRD) e, com o auxílio de estatísticas, foi possível engendrar o modelo pioneiro de proteção social para o Estado do bem-estar, em que a assistência se resumia a manter o indivíduo no que concerne a sobrevivência.

A corrente das necessidades básicas, embalada pela perspectiva da subsistência, trouxe alguns avanços no entendimento da pobreza por volta nos anos 1950 e 1970. Essa noção, além de abordar o mínimo necessário que uma família necessita em privado como alimento e roupa, traz a obrigatoriedade de serviços oferecidos tradicionalmente pelo Estado como educação, saúde, saneamento básico e moradia. "O conceito de necessidades básicas se apresenta como uma extensão do de subsistência" (CODES, 2008, p.13), proporciona a incorporação de questões ligadas, mais propriamente, a uma coletividade e não somente, como é o caso da primeira perspectiva, questões mais ligadas às dimensões individuais e privadas.

Para Rocha (2006, p.20), essa perspectiva contraria a primeira abordagem em três sentidos. O primeiro se refere ao abandono da renda como critério único de delimitação dos pobres e não pobres, em decorrência da sua imprecisão e se refere também ao interesse de promover parâmetros que reflitam a qualidade de vida, não uma abordagem que adota questões mais instrumentais. O segundo sentido é relativo ao desenvolvimento de instrumentos de análise capazes de determinar comparações entre países e observar o atendimento das necessidades básicas em uma população como um todo. Não se trata aqui de estabelecer um grupo preferencialmente pobre, mas de analisar a sociedade como um todo. Já o terceiro sentido, é a adoção de um caráter multifacetado da pobreza, que tem finalidade a promoção de políticas que visam as diferentes e diversas carências e a "melhoria do bem-estar social [que] deve ser mais do que o resultado da soma de atuações setoriais especificas e desvinculadas entre si" (ROCHA, 2006, p.20).

Com o debate dessa concepção em diferentes campos da economia, foi possível situar essa abordagem no desenvolvimento econômico e social de uma nação e a sua compreensão se dá na "independência nacional, da dignidade de indivíduos e povos, e de suas liberdades" (CODES, 2008, p.13), para que, com isso, cada ser humano possa prosperar sem qualquer tipo de entrave. Segundo Townsend (1993 apud Codes, 2008, p.14), apesar da noção de necessidades básicas não incorporar o aspecto multidimensional necessário para o combate eficiente da pobreza, possibilitou a discussão do "direito de acesso" de toda a sociedade no que tange a moradia, alimentação e serviços essenciais e também a discussão da desigualdade entre os indivíduos. Esses temas, apesar de se encaixarem na complexidade social humana e de serem essenciais para a compreensão estrutural e social da pobreza, ainda possuem limitações, uma vez que sua abordagem não permite a inserção de certas coletividades e minorias, como idosos e mulheres .

A perspectiva da privação relativa que, segundo Crespo e Gurovitz (2002), começou a ser desenvolvida a partir de 1980, introduziu na discussão sobre pobreza o contexto social em que as pessoas estão situadas, visto que com o decorrer dos anos as sociedades mudam e se observa que padrões e normas relativas ao passado não são necessariamente recorrentes no presente ou no futuro. Para a concepção da privação relativa, pobres são aquelas pessoas que "não podem obter, de todo ou suficientemente, recursos e condições de vida (...) que lhes permitam desempenhar papéis, participar de relacionamentos e seguir o comportamento que lhes é esperado enquanto membros da sociedade" (CODES, 2008, p.15-16). Essa definição deixa explícito o papel inerente entre pobreza e cidadania, dado que negação de direitos de cidadania pode possibilitar a exclusão de um indivíduo ou de uma coletividade de certa completude social e/ou econômica, o que pode levar a certos quadros de pobreza. No cerne do combate à pobreza está a busca por uma sociedade baseada na justiça e equidade e por direitos de cidadania, mesmo que não plenos. É no campo social e institucional que o estudo da pobreza deve-se enquadrar, e não somente no quadro de baixa renda, uma vez que é por meio da ótica da privação relativa que o estudo da pobreza recai naqueles que realmente necessitam de acompanhamento, naqueles indivíduos que são privados social e materialmente em diversos pontos (TOWNSEND, 1993, p. 35-36 apud CODES, 2008, p.17).

Com o surgimento da abordagem das capacitações, desenvolvida pelo economista indiano Amartya Sen e por Martha Nussbaum, a pobreza passa a ser de várias dimensões. Amartya Sen desenvolveu a Abordagem das Capacitações no que era pertinente à Economia; Martha Nussbaum a desenvolveu na linha da Filosofia Política. Essa abordagem fomenta uma ruptura com a visão tradicional do bem-estar, ampliando e transformando, principalmente, as noções relativas a indivíduo, renda e bem-estar. (GASPER, 1997 apud GIACOMELLI; MARIN; FEISTEL, 2017, p.96-97).

Essa nova concepção introduz a noção de capacitações básicas e funcionamentos, promove a elaboração de conceitos como justiça social e desigualdade. Segundo Sen (2001, p.79), os funcionamentos correspondem a "estados" e "ações", isto é, em um sentido amplo, se referem às atividades relacionadas ao fazer ou ao funcionar de uma pessoa que podem variar de situações mais simplórias como ser capaz de ler, escrever, estar bem nutrido e livre de doenças até situações mais complexas como ser feliz e ter respeito próprio. As capacitações, como explicitou o próprio Sen (2001, p.79-80), 
representam um conjunto de vetores de funcionamentos, ou seja, inúmeras combinações de funcionamentos, que refletem "a liberdade da pessoa para levar um tipo de vida ou outro" e dependem de vários fatores inclusive características pessoais e combinações sociais. Alicerçado, portanto, no conceito de funcionamentos, o conjunto capacitário espelha a liberdade do indivíduo para escolher qual tipo de vida deseja perseguir.

De acordo com Giacomelli, Marin e Feistel (2017), Sen argumenta que na Abordagem das Capacitações, uma vez que se tem como elemento central os funcionamentos, têm-se as variáveis responsáveis por analisar o próprio bem-estar. Diferentemente do que acontece com as teorias tradicionais que focam, geralmente, os meios para se alcançar o bem-estar tais como a riqueza de um país ou a riqueza individual, os bens primários e acesso a recursos.

A abordagem das capacitações não contribui somente para a análise do bem-estar, mas também para investigar a pobreza e o desenvolvimento socioeconômico. No que tange a pobreza, é importante salientar que Sen de modo algum deixa de lado seu caráter econômico e por si só pioneiro, seu objetivo é discutir de maneira veemente traços da pobreza que são, geralmente, ignorados pelas teorias tradicionais, traços esses que se referem a um caráter mais social e dinâmico.

Esse autor percebe a relação íntima entre bem-estar e estar bem e que a pobreza é relativa à "falta de realização de certos funcionamentos de base e da aquisição das capacidades correspondentes" (CODES, 2008, p.20). Sen compreende a pobreza como privação das capacitações básicas, uma vez que essas capacitações representam as condições mínimas ou dos funcionamentos primários aos funcionamentos mais complexos. A perspectiva das capacitações tem como foco melhorar "o entendimento da natureza e das causas da pobreza e privação desviando a atenção principal dos meios (...) para os fins que as pessoas têm razão para buscar e (...) para as liberdades de poder alcançar esse fim” (SEN, 2000, p. 112). A importância para Sen do estudo da pobreza sob essa ótica se encontra "no fato de que as privações são vistas em um nível mais fundamental, mais próximo das demandas de justiça social” (CODES, 2008, p.23) e é por meio de uma confluência de capacitações básicas que se encontra uma alternativa de mensurar e diagnosticar a pobreza.

A pobreza é, atualmente, considerada um fenômeno multidimensional e complexo, visto que se refere, além do que é usualmente tido como pobreza - à falta de bens materiais e de bem-estar -, a aspectos enquadrados nos "padrões aceitáveis socialmente" (CODES, 2008, p.24). Essa definição de pobreza é defendida por inúmeros autores que enfatizam sua capacidade de não se restringir somente à renda, mas também a outras questões como direitos sociais, igualdade entre sexos e educação (MESTRUM, 2002, p. 37 apud CODES, 2008, p.24).

Mesmo com a emergência de um critério multidimensional no estudo da pobreza, é importante analisar e estudar as primeiras medidas, isto é, medidas unidimensionais, uma vez que elas podem ajudar a compreender a pobreza em toda a sua complexidade. A próxima seção, portanto, trata desse tipo de medida da pobreza.

\subsection{As medidas de pobreza}

Rowntree (1901; Rowntree, 1941; Rowntree, Lavers, 1951; Townsend, 1962 apud Rocha 2006, p.13) foi o primeiro a elaborar um parâmetro de valor para definir linha de pobreza, que agregou o aspecto absoluto e o relativo. O autor elaborou uma linha de pobreza para a cidade de York, Inglaterra, e pretendia conceituar essa linha como sendo absoluta - se referindo ao mínimo para a manutenção física. Todavia, quando no momento de elaborar um valor para atender a itens específicos, tais itens iam de encontro com as questões sociais da cidade, o que em si já se configura como relativo.

Quando se é estabelecido um valor monetário correspondente ao atendimento das necessidades médias nutricionais de um indivíduo, tem-se a linha de indigência e quando isso é feito a partir de um conjunto mais abrangente de necessidades tem-se a linha de pobreza. Uma pessoa pobre é aquela que possui renda abaixo do valor estabelecido e uma pessoa indigente é aquela em que a renda não é suficiente para atender apenas as questões de necessidades nutricionais, sendo, portanto, um subconjunto dos pobres. (ROCHA, 2006, p. 12-13).

A partir da definição da linha de pobreza, o Banco Mundial (2005) apresenta as medidas tradicionais de pobreza: proporção dos pobres, hiato médio de pobreza, hiato quadrático de pobreza e índice de Sen. A proporção dos pobres (P_0) mede a proporção da população considerada pobre, ou seja, mede a porcentagem de indivíduos com renda per capita abaixo da linha de pobreza. O resultado dessa medida varia de 0 a 1; 0 significa a ausência de pobres e 1 a população inteira é pobre. O hiato médio de pobreza ( $\mathrm{P}_{-}$1) mede a intensidade da pobreza para um grupo da sociedade e trabalha com a renda dos indivíduos pobres e com o valor da linha da pobreza, varia de 0 (ausência de pobres) e 1 (população inteira pobre). O hiato quadrático de pobreza mede a severidade da pobreza ou; mede o quadrado do hiato da pobreza em referência a linha de pobreza, além de usar a desigualdade de renda e um peso maior para os mais pobres. O índice de Sen incorpora a distribuição de renda, a profundidade da pobreza e o número de pobres.

Apesar de cada uma dessas medidas trazerem algum tipo de evolução, permaneciam na lógica binária de pobres e não pobres e no critério da renda, ignorando outros aspectos que interferem e que determinam se alguém é, em um sentido amplo, pobre.

O Índice de Desenvolvimento Humano (IDH) foi apresentado pelo Relatório de Desenvolvimento Humano (RDH) de 1990 a partir do entendimento do desenvolvimento humano como um processo de alargamento das escolhas dos 
indivíduos, que englobam questões primordiais como a de ter uma vida saudável e longa, de receber instrução e de dispor de um padrão de vida digno até questões mais secundárias ou adicionais que incorporam a liberdade política, os direitos humanos e o respeito próprio. A partir desse conceito mais abrangente, o IDH passa a ser formulado por meio de uma medida composta de três dimensões, a saber, saúde, educação e padrões de vida e por quatro indicadores, esperança de vida à nascença, média dos anos de escolaridade, anos de escolaridade esperados e rendimento nacional bruto per capita.

O IDH ajuda na análise de algumas questões básicas sobre o progresso das sociedades, mas de acordo com o RDH (1997), não foi suficiente para o estudo da pobreza nos países, uma vez que as médias usadas encobrem a ocorrência de situações extremas associadas à desigualdade de bem-estar entre indivíduos. O RDH (1997) introduz o Índice de Pobreza Humana (IPH) como uma tentativa de promover um índice que tenha por base os diversos aspectos da pobreza. O IPH se concentra nas três dimensões básicas: longevidade ou esperança de vida, educação e um padrão de vida digno; e é desenvolvido de diferente modo nos países desenvolvidos, IPH-2, e nos países em desenvolvimento, IPH-1.

Segundo o RDH (1997) a primeira dimensão do IPH-1 se relaciona com certa vulnerabilidade à morte em uma idade precoce, por isso agrega a proporção de pessoas que tem uma esperança de vida menor do que 40 anos. A segunda dimensão, a educação, trata daquelas pessoas excluídas do mundo da comunicação e da leitura e incorpora a porcentagem de adultos analfabetos. O terceiro aspecto tenta refletir um padrão decente de vida e é composto por três variáveis: a proporção de pessoas sem acesso a serviços de saúde e a água tratada e a proporção de crianças desnutridas menores de cinco anos. O IPH-2, possui os indicadores probabilidade de esperança de vida menor do que 60 anos, porcentagem de adultos analfabetos funcionais e proporção de pessoas que possuem renda per capita inferior a $50 \%$ da renda mediana do país, os considerados pobres, e taxa de desemprego de longa duração (acima dos 12 meses). Esse último indicador está relacionado com a dimensão da exclusão social.

A diferença entre o IDH e o IPH, segundo Anand e Sen (1997), é que o IDH se enquadra em uma perspectiva conglomerativa, uma vez que investiga o desenvolvimento humano, isto é, foca na qualidade de vida dos indivíduos em geral, que pode ser explorado junto com a perspectiva da privação, e tem como um dos alicerces o PNB. Já o IPH trata propriamente da dimensão da privação, ou seja, analisa aqueles que sofrem de fato privações e que são multidimensionalmente pobres. Anand e Sen (1997) enfatizam que o IPH não substitui o IDH, mesmo ambos compartilhando características do desenvolvimento humano.

O RDH (2010) apresenta o Índice de Pobreza Multidimensional (IPM) que tem por base o trabalho de Alkire e Santos (2010). Esse índice é fruto da contagem da pobreza multidimensional; da quantidade de indivíduos que são pobres em termos multidimensionais, e do número médio de privações que cada família pobre sofre. O IPM inclui as dimensões saúde, educação e padrões de vida que são refletidos em dez indicadores, nutrição, mortalidade infantil, anos de escolaridade, crianças matriculadas, combustível de cozinha, sanitários, água, eletricidade, pavimento e ativos. O IPM substitui o IPH, devido à ineficiência desse último índice em identificar grupos específicos, famílias ou indivíduos que sofrem privações em conjunto. Uma família é multidimensionalmente pobre se sofrer privações, pelo menos, em dois até seis indi $\neg$ cadores. Segundo o RDH (2010), essas séries de dimensões são incluídas a partir de exercícios participados entre as comunidades pobres e do consenso internacional.

Em 2012, o Programa das Nações Unidas para o Desenvolvimento no Brasil (PNUD Brasil), o Instituto de Pesquisa Econômica Aplicada (Ipea) e a Fundação João Pinheiro desenvolveram o Índice de Desenvolvimento Humano Municipal (IDHM), uma adaptação da metodologia do IDH Global ao contexto brasileiro e à disponibilidade de indicadores nacionais com o objetivo de calcular o IDH dos 5.565 municípios brasileiros. O cálculo foi feito a partir das informações dos três últimos Censos Demográficos do $\operatorname{IBGE}(1991,2000$ e 2010) e segundo a malha municipal existente em 2010. As dimensões que compõem o IDHM brasileiro são longevidade, educação e renda. Devido à adaptação das dimensões ao contexto brasileiro e apesar do IDHM e do IDHM Global medirem os mesmos fenômenos, os indicadores levados em conta no IDHM são mais adequados para analisar e observar o desenvolvimento dos municípios e regiões metropolitanas brasileiras.

Como o objetivo do presente estudo é aplicar o método Alkire-Foster em Santa Catarina, é essencial caracterizar o respectivo estado.

\section{Santa Catarina: uma breve descrição}

Santa Catarina, localizada na Região Sul do Brasil, tem uma população de 6.248 .436 habitantes, de acordo com o Censo 2010, que são distribuídos em 295 municípios em uma área de $95733,98 \mathrm{~km}^{2}$ e com densidade demográfica de $65,27 \mathrm{hab} / \mathrm{km}^{2}$. Segundo o IBGE (1990), o estado pode ser dividido em seis mesorregiões e em vinte microrregiões . A figura 1 mostra o estado catarinense com a divisão em Mesorregiões estabelecidas pelo IBGE.

Santa Catarina possui um IDHM em 2010 considerado alto , de 0,774 e ocupa a terceira posição entre os 26 estados 
brasileiros e o Distrito Federal, segundo o ranking desse índice, perde somente para o Distrito Federal que tem um IDHM (2010) muito alto de 0,824 e para São Paulo que registra um índice (2010) de 0,783. A tabela 1 compara o IDHM brasileiro com cada estado da Região Sul nos anos de 1991, 2000 e 2010.

\section{Figura 1 - Mapa da Distribuição Espacial das Secretarias de Desenvolvimento Regionais (SDR) e das Mesorregiões} de Santa Catarina

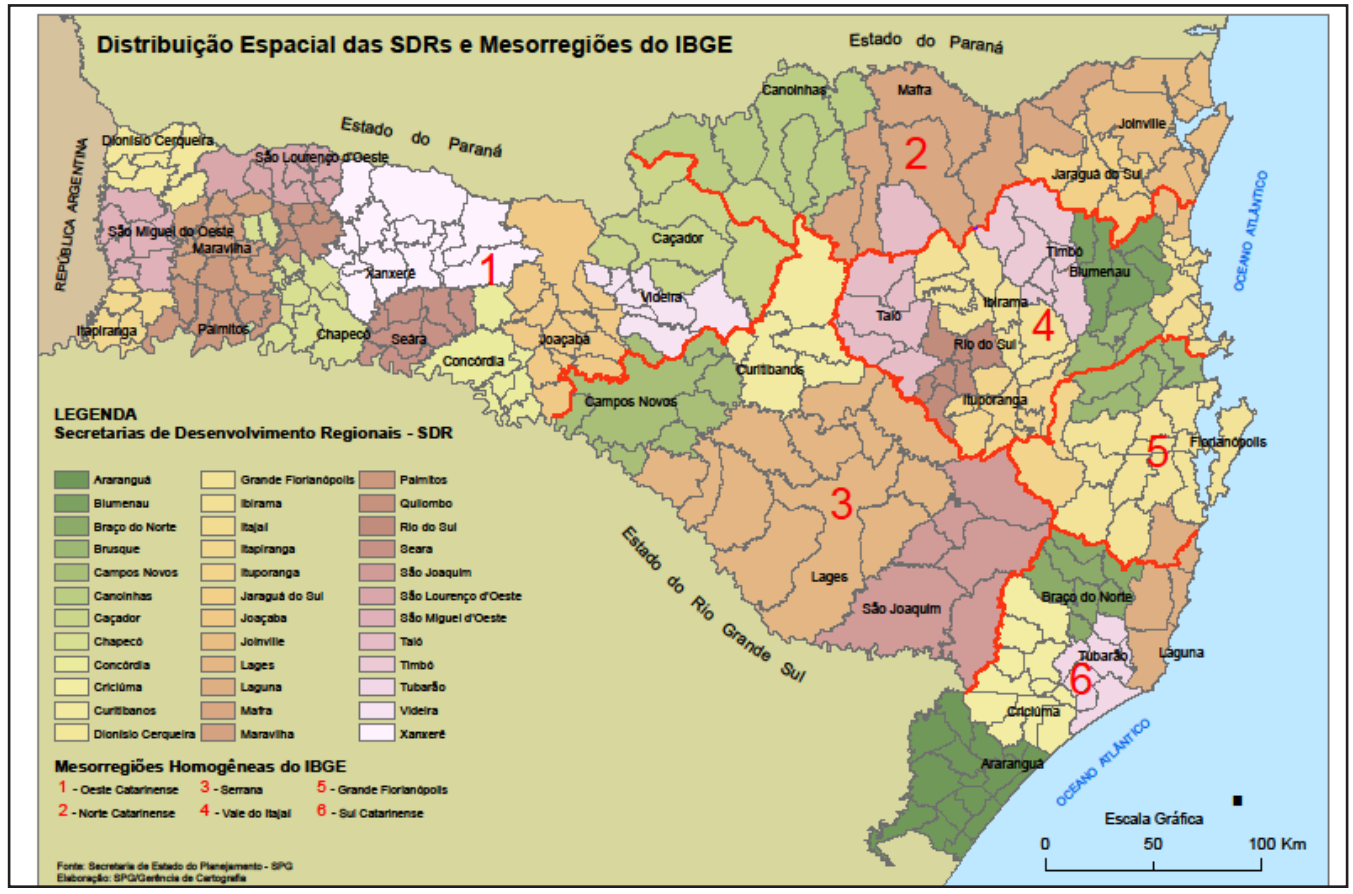

Fonte: FAPESC (2013)

Tabela 1 - Comparação do IDHM no Brasil e nos estados da Região Sul

\begin{tabular}{l|c|c|c}
\hline & IDHM 1991 & IDHM 2000 & IDHM 2010 \\
\hline Brasil & 0,493 & 0,612 & 0,727 \\
\hline Paraná & 0,507 & 0,65 & 0,749 \\
\hline Rio Grande do Sul & 0,542 & 0,664 & 0,746 \\
\hline Santa Catarina & 0,543 & 0,674 & 0,774 \\
\hline
\end{tabular}

Fonte: Atlas do Desenvolvimento Humano do Brasil (2013)

Todos os estados da Região Sul nos anos analisados registraram um IDHM superior ao IDHM nacional com destaque para o estado de Santa Catarina que, comparado aos outros estados da Região Sul, registra em todos os anos o maior índice da região. De 1991 a 2010, o IDHM de Santa Catarina obteve uma taxa de crescimento de 42,53\%, passou de 0,543 para 0,774 e o IDHM do Brasil registrou uma taxa de crescimento de 47\% passou de 0,493 para 0,727. O Rio Grande do Sul teve uma taxa de crescimento menor se comparado aos estados vizinhos e ao Brasil, de 37,74\%, indo de 0,542 para 0,746 e o estado paranaense teve a maior taxa de crescimento nessa comparação, de $47,73 \%$, indo de 0,507 para 0,749 .

As dimensões que compõem do IDHM são renda, longevidade e educação. A dimensão renda para Santa Catarina possui índice de 0,773, a dimensão longevidade tem índice de 0,860 e a dimensão educação com 0,697 todas registradas para o ano de 2010. Se comparada com anos anteriores (1991 e 2000), o estado sofreu melhoras principalmente no componente educação que em 1991 registrava um índice de 0,329 e em 2010 saltou para 0,697. Os componentes longevidade e educação sofreram melhoras não tão expressivas, porém já em 1991 esse primeiro componente registrava um índice alto, de 0,753 e o segundo um índice médio de 0,648. Vale destacar também que em todos os anos analisados $(1991,2000$ e 2010) a longevidade foi a dimensão que mais contribuiu para o IDHM do estado tendo um índice de 0,812 em 2000 e de 0,86 em 2010. 
Tabela 2 - Evolução dos componentes do IDHM para os anos de 1991, 2000 e 2010

\begin{tabular}{|c|c|c|c|}
\hline IDHM e componentes & 1991 & 2000 & 2010 \\
\hline IDHM Educação & 0,329 & 0,526 & 0,697 \\
\hline$\%$ de 18 anos ou mais com fundamental completo & 31,79 & 41,48 & 58,87 \\
\hline$\%$ de 5 a 6 anos na escola & 31,76 & 73,59 & 91,17 \\
\hline $\begin{array}{l}\% \text { de } 11 \text { a } 13 \text { anos nos anos finais do fundamental regular seriado ou } \\
\text { com fundamental completo }\end{array}$ & 53,61 & 76,36 & 91,51 \\
\hline$\%$ de 15 a 17 anos com fundamental completo & 31,38 & 54,02 & 69,19 \\
\hline$\%$ de 18 a 20 anos com médio completo & 17,01 & 33,39 & 51,8 \\
\hline IDHM Longevidade & 0,753 & 0,812 & 0,86 \\
\hline Esperança de vida ao nascer & 70,16 & 73,69 & 76,61 \\
\hline IDHM Renda & 0,648 & 0,717 & 0,773 \\
\hline Renda per capita & 449,78 & 693,82 & 983,9 \\
\hline
\end{tabular}

Fonte: Atlas do Desenvolvimento Humano do Brasil (2013)

A população de Santa Catarina entre 2000 e 2010 cresceu a uma média anual de 1,55\%, uma taxa menor do que se comparado ao período de 1991 a 2000, que foi de 1,85\%. Em 1991, a população urbana correspondia a 70,64\% da população total que no período era de 4.541 .994 de habitantes. Em 2000, a uma população total de 5.356 .360 habitantes, a população urbana já correspondia a $78,75 \%$ e em $2010 \mathrm{com} 6.248 .436$ habitantes, a população urbana foi para quase $84 \%$. No que se refere à população por gênero, o número de mulheres e o número de homens nos anos analisados sempre foram próximos. A população feminina representava 49,90\% da população em 1991 e 50,38\% em 2010. A população masculina que em 1991 representava 50,10\% da população teve uma leve redução para 46,62 em 2010.

Tabela 3 - População Total, por Gênero, Rural/Urbana - Estado - Santa Catarina

\begin{tabular}{l|c|c|c|c|c|c}
\hline População & $\begin{array}{c}\text { População } \\
(1991)\end{array}$ & $\begin{array}{c}\text { \% do Total } \\
(1991)\end{array}$ & $\begin{array}{c}\text { População } \\
(2000)\end{array}$ & $\begin{array}{c}\text { \% do Total } \\
(2000)\end{array}$ & $\begin{array}{c}\text { População } \\
(2010)\end{array}$ & $\begin{array}{c}\text { \% do Total } \\
(2010)\end{array}$ \\
\hline População total & 4.541 .994 & 100 & 5.356 .360 & 100 & 6.248 .436 & 100 \\
\hline $\begin{array}{l}\text { População residente } \\
\text { masculina }\end{array}$ & 2.275 .714 & 50,1 & 2.669 .311 & 49,83 & 3.100 .360 & 49,62 \\
\hline $\begin{array}{l}\text { População residente } \\
\text { feminina }\end{array}$ & 2.266 .280 & 49,9 & 2.687 .049 & 50,17 & 3.148 .076 & 50,38 \\
\hline População urbana & 3.208 .537 & 70,64 & 4.217 .931 & 78,75 & 5.247 .913 & 83,99 \\
\hline População rural & 1.333 .457 & 29,36 & 1.138 .429 & 21,25 & 1.000 .523 & 16,01 \\
\hline
\end{tabular}

Fonte: Atlas do Desenvolvimento Humano do Brasil (2013)

A mortalidade infantil, ou seja, a mortalidade de crianças com menos de um ano de idade, em Santa Catarina passou de 24,8 óbitos por mil nascidos vivos em 1991 para 11,5 óbitos por mil nascidos vivos em 2010. No Brasil, a taxa de mortalidade infantil em 1991 foi de 44,7 óbitos por mil nascidos vivos para 16,7 óbitos por mil nascidos vivos em 2010, cumprindo uma das metas dos Objetivos de Desenvolvimento do Milênio das Nações Unidas na qual a mortalidade infantil deve estar abaixo de 17,9 óbitos por mil nascidos vivos em 2015. A esperança de vida ao nascer, indicador utilizado para compor a dimensão longevidade do IDHM, cresceu 6,4 anos no período entre 1991 a 2010. Em 1991, a esperança de vida era de 70,2 anos, em 2000 era de 73,7 anos e em 2010 de 76,6 anos. 
Tabela 4 - Longevidade, Mortalidade e Fecundidade em Santa Catarina

\begin{tabular}{l|l|l|l}
\hline & 1991 & 2000 & 2010 \\
\hline Esperança de vida ao nascer & 70,2 & 73,7 & 76,6 \\
\hline Mortalidade infantil & 24,8 & 16,8 & 11,5 \\
\hline Mortalidade até 5 anos de idade & 28,6 & 19,4 & 13,4 \\
\hline Taxa de fecundidade total & 2,6 & 2,2 & 1,7 \\
\hline
\end{tabular}

Fonte: Atlas do Desenvolvimento Humano do Brasil (2013)

O componente educação do IDHM é composto pelas proporções de crianças e jovens (população em idade escolar) que frequentam ou que já tenham concluído determinados ciclos escolares. A proporção de crianças de 5 a 6 anos na escola aumentou 59,41 pontos percentuais de 1991 a 2010 passando de $31,76 \%$ para $91,17 \%$ e a proporção de crianças de 6 a 14 frequentando as fases finais do ensino fundamental foi de 80,83\% em 1991 para 97,82\% em 2010, um aumento de quase 17 pontos percentuais. A proporção de jovens de 15 a 17 anos frequentando a escola passou de 45,22\% em 1991 para 80,18\% em 2010, um aumento de 34,96 pontos percentuais.

O IDHM educação também é composto por um indicador referente à educação da população adulta. Esse indicador é o percentual da população de 18 anos ou mais com o ensino fundamental completo. A proporção da população de 18 anos ou mais com o ensino fundamental completo passou de 31,79\% em 1991 para 58,87\% em 2010. A proporção de pessoas de 18 anos ou mais com o ensino médio completo saltou de 16,77\% em 1991 para 40,41\% em 2010 e a proporção da população de 25 anos ou mais com ensino superior completo foi de 4,76\% em 1991 para 12,53\% em 2010.

É possível também analisar a frequência escolar a partir da expectativa de anos de estudo da população em idade escolar. Em Santa Catarina, essa expectativa passou de 9,93 anos em 1991 para 10,13 anos em 2000 e para 10,24 anos em 2010. A nível nacional, passou de 8,16 anos em 1991 para 8,76 anos em 2000 e para 9,54 anos em 2010.

A renda per capita média do estado catarinense cresceu 118,75\% entre os anos de 1991 a 2010: em 1991 a renda era de $\mathrm{R} \$ 449,78$, em 2000 era de $\mathrm{R} \$ 693,82$ e em 2010 de $\mathrm{R} \$ 983,9$. Já a desigualdade de renda pode ser medida por meio do Índice de Gini que foi de 0,55 em 1991 para 0,49 em 2010.

Tabela 5 - Renda, Pobreza e Desigualdade em Santa Catarina

\begin{tabular}{l|l|l|l}
\hline & 1991 & 2000 & 2010 \\
\hline Renda per capita & 449,78 & 693,82 & 983,9 \\
\hline$\%$ de extremamente pobres & 9,26 & 3,82 & 1,01 \\
\hline$\%$ de pobres & 25,32 & 12,79 & 3,65 \\
\hline Índice de Gini & 0,55 & 0,56 & 0,49 \\
\hline
\end{tabular}

Fonte: Atlas do Desenvolvimento Humano do Brasil (2013)

No que se refere aos indicadores de habitação - água encanada, energia elétrica e coleta de lixo - já em 1991 a proporção de domicílios que tinham pelos menos um desses indicadores era alta. Domićlíos com água encanada em 1991 correspondia a $90,41 \%$ do total e em 2010 a 94,13\%, com energia elétrica em 1991 a proporção era de 94,62\% e em 2010 de 99,81 e domicílios com coleta de lixo passou de 84,09\% em 1991 para 99,31\% em 2010.

Tabela 6-Indicadores de habitação em Santa Catarina

\begin{tabular}{l|l|l|l}
\hline & 1991 & 2000 & 2010 \\
\hline \% da população em domicílios com água encanada & 90,41 & 94,39 & 94,13 \\
\hline \% da população em domicílios com energia elétrica & 94,62 & 98,58 & 99,81 \\
\hline \% da população em domićlios com coleta de lixo & 84,09 & 96,78 & 99,31 \\
\hline
\end{tabular}

Fonte: Atlas do Desenvolvimento Humano do Brasil (2013)

A tabela 7 mostra a situação de vulnerabilidade social no estado de Santa Catarina, o que inclui índices de mortalidade infantil, proporção das crianças e jovens na escola, taxa de atividade da população entre 10 a 14 anos, situação de mães como chefe de família, proporção da população vulnerável à pobreza, proporção de pessoas de 18 anos ou mais sem fundamental completo 
e em ocupação informal e proporção da população em domicílios com banheiro e água encanada entre outros indicadores.

Em 2010 quase 50\% das crianças de 0 a 5 anos estavam fora da escola, proporção bem maior do que se comparada a de crianças de 6 a 14 anos fora da escola no mesmo ano de 2,18\%. Em 1991 49,43\% da população de Santa Catarina era considerada vulnerável à pobreza, já em 2010, essa proporção reduziu para 12,36\%. No que se refere às condições de moradia, em 2010 apenas $3 \%$ da população vivia em domicílios sem banheiro e sem água encanada. Em 1991, essa proporção era de 20,03\%.

Tabela - Vulnerabilidade Social em Santa Catarina

\begin{tabular}{|c|c|c|c|}
\hline Crianças e Jovens & 1991 & 2000 & 2010 \\
\hline Mortalidade infantil & 24,84 & 16,79 & 11,54 \\
\hline$\%$ de crianças de 0 a 5 anos fora da escola & - & 73,61 & 49,80 \\
\hline$\%$ de crianças de 6 a 14 fora da escola & 19,17 & 4,62 & 2,18 \\
\hline $\begin{array}{l}\text { \% de pessoas de } 15 \text { a } 24 \text { anos que não estudam, não trabalham e são vulneráveis, na } \\
\text { população dessa faixa }\end{array}$ & - & 9,24 & 3,75 \\
\hline$\%$ de mulheres de 10 a 17 anos que tiveram filhos & 2,22 & 2,85 & 2,21 \\
\hline Taxa de atividade - 10 a 14 anos & - & 10,91 & 8,69 \\
\hline \multicolumn{4}{|l|}{ Família } \\
\hline $\begin{array}{l}\text { \% de mães chefes de família sem fundamental e com filho menor, no total de mães chefes } \\
\text { de família }\end{array}$ & 8,47 & 10,00 & 13,99 \\
\hline$\%$ de vulneráveis e dependentes de idosos & 2,41 & 1,55 & 0,76 \\
\hline$\%$ de crianças extremamente pobres & 12,87 & 6,54 & 1,93 \\
\hline \multicolumn{4}{|l|}{ Trabalho e Renda } \\
\hline \% de vulneráveis à pobreza & 49,34 & 31,40 & 12,36 \\
\hline$\%$ de pessoas de 18 anos ou mais sem fundamental completo e em ocupação informal & - & 41,83 & 26,87 \\
\hline \multicolumn{4}{|l|}{ Condição de Moradia } \\
\hline \% da população em domicílios com banheiro e água encanada & 79,97 & 91,82 & 97,00 \\
\hline
\end{tabular}

Fonte: Atlas do Desenvolvimento Humano do Brasil (2013)

No que se refere ao IDHM Longevidade dos municípios do estado catarinense em 1991, apenas quatro cidades possuíam um índice muito alto, entre 0,800 a 1000: Cunhataí, Massaranduba, Guabiruba e Urussanga. Os índices mais baixos do IDHM Longevidade 1991, entre 0,600 a 0,699, estão localizados em oito cidades da Mesorregião Oeste Catarinense (Flor do Sertão, São Bernardino, Campo Erê, Coronel Martins, Ipuaçu, Ouro Verde, Entre Rios e Calmon), em seis cidades da Mesorregião Norte Catarinense (Bela Vista do Toldo, Timbó Grande, Itaiópolis, Três Barras, Monte Castelo, Papanduva), e em oito cidades da Mesorregião Serrana (Santa Cecília, Ponte Alta, Frei Rogério, Campo Belo do Sul, Cerro Negro, São José do Cerrito, Capão Alto, Rio Rufino). Todos os outros municípios catarinenses possuem um índice entre 0,700 a 0,799 no mesmo ano. Em 2000, todas as cidades catarinenses registravam índices alto ou muito alto. Em 2010, quinze cidades não conseguiram atingir um índice muito alto. São elas: Campo Erê, Bandeirante, Santa Terezinha do Progresso, São Miguel da Boa Vista, Flor do Sertão, Ipuaçu, Ouro Verde, Ponte Serrada, Calmon, Timbó Grande, Vargem, Campo Belo do Sul, Capão Alto, Bocaina do Sul e Angelina. Os índices desses municípios ficaram entre 0,768 a 0,798 .

No que se refere ao IDHM Educação 1991, a ilha de Florianópolis registrava o maior índice de 0,538, considerado um índice baixo. Todas as outras cidades do estado possuíam um IDHM Educação na faixa de 0,000 a 0,499, indicado como muito baixo, sendo que o menor índice era o do município de Vargem na Mesorregião Serrana com 0,072. Em 2000, oito cidades conseguiram alçar um índice médio, no intervalo de 0,600 a 0,699: Florianópolis, Tubarão, Cocal do Sul, Balneário Camboriú, Blumenau, Jaraguá do Sul, Schroeder e Joaçaba. Setenta e três cidades possuíam um índice na faixa de 0,500 a 0,599 e as outras duzentos e quatorze cidades possuíam um índice muito baixo, de 0,000 a 0,499 . O menor índice de 2000 foi o da cidade de Calmon na Mesorregião Oeste Catarinense com 0,217. Em 2010, somente três cidades ainda permaneciam com um IDHM Educação muito baixo: Vargem, Alfredo Wagner e Cerro Negro.

Em relação ao IDHM Renda 1991, cinco municípios catarinenses possuíam um índice alto, na faixa de 0,700 a 0,799: Florianópolis, Joaçaba, Balneário Camboriú, Blumenau e Jaraguá do Sul. Trinta e três cidades registravam um índice muito baixo, sendo o menor índice o da cidade de Tigrinhos com 0,418. Em 2000, apenas Florianópolis e Balneário Camboriú mostraram um índice na faixa considerada muito alto. Florianópolis com 0,828 e Balneário Camboriú com 0,848 . E apenas a cidade de Entre Rios na Mesorregião Oeste Catarinense possuía um índice muito baixo de 0,490. Em 2010, foram 
registradas nove cidades com IDHM Renda muito alto; Florianópolis e Balneário Camboriú permaneceram nessa faixa, sendo acompanhados por Rio Fortuna, Blumenau, Timbó, Treze Tílias, Joaçaba, Presidente Castello Branco e Seara. Os menores índices foram das cidades de Calmon e São José do Cerrito ambas com índice 0,618.

\section{Método Alkire-Foster para Santa Catarina (2000-2010)}

Essa etapa do trabalho compreende o cálculo da medida de pobreza multidimensional para os municípios de Santa Catarina, nos anos de 2000 e 2010, por meio do método Alkire-Foster (AF) (2009). Para isso, usou-se o software Stata para o cálculo e compati $\neg$ bilização dos dados por meio do Data Zoom que disponibiliza gratuitamente ferramentas que facilitam a utilização dos micro $\neg$ dados domiciliares do IBGE. Os resultados são apresentados por meio de mapas elaborados com o software QGIS.

Uma das etapas mais importantes para usar o método AF é determinar as dimensões e seus respectivos indicadores. Em vista disso, se fez uma seleção de alguns trabalhos que já analisaram a perspectiva multidimensional da pobreza seja no Brasil como um todo seja nos estados da Federação, destacando as dimensões e os indicadores (tabela 8).

Tabela 8 - Dimensões usadas em outros estudos no Brasil

\begin{tabular}{|c|c|c|c|}
\hline Unidade de análise & Autores & Medida & Dimensões \\
\hline Brasil & $\begin{array}{c}\text { Fahel, Teles e } \\
\text { Caminhas (2016) }\end{array}$ & $\begin{array}{l}\text { IPM global proposta por } \\
\text { Alkire e Foster (2011a, } \\
\text { 2011b) }\end{array}$ & Educação, saúde, padrão de vida \\
\hline Brasil & $\begin{array}{l}\text { Lopes, Macedo e } \\
\text { Machado (2003) }\end{array}$ & $\begin{array}{l}\text { Índice de Pobreza baseado } \\
\text { em Costa (2002) e na teoria } \\
\text { dos conjuntos fuzzy. }\end{array}$ & $\begin{array}{l}\text { Renda domiciliar per capita, } \\
\text { infraestrutura domiciliar, nível } \\
\text { de escolaridade, moradores em } \\
\text { situação precária }\end{array}$ \\
\hline Brasil & $\begin{array}{c}\text { Silva, Araújo, } \\
\text { Campelo et al (2014) }\end{array}$ & $\begin{array}{c}\text { Índice de Pobreza } \\
\text { Multidimensional baseado } \\
\text { no método de Bourguignon e } \\
\text { Chakravarty (2003). }\end{array}$ & $\begin{array}{c}\text { Alimentos e água, comunicação e } \\
\text { informação, educação, condições } \\
\text { de moradia, saúde, trabalho e } \\
\text { demografia }\end{array}$ \\
\hline Nordeste & $\begin{array}{l}\text { Ottonelli e Mariano } \\
\text { (2014) }\end{array}$ & $\begin{array}{l}\text { O índice } f u z z y \text { da pobreza } \\
\text { multidimensional. }\end{array}$ & $\begin{array}{l}\text { Educação, saúde, condições } \\
\text { habitacionais e renda }\end{array}$ \\
\hline Paraná & $\begin{array}{l}\text { Giovanetti e Raiher } \\
\text { (2015) }\end{array}$ & $\begin{array}{l}\text { Indicador de pobreza } \\
\text { multidimensional usando o } \\
\text { método fuzzy. }\end{array}$ & $\begin{array}{l}\text { Renda, educação, saúde/social, } \\
\text { infraestrutura }\end{array}$ \\
\hline Bahia & $\begin{array}{l}\text { Leite, Silva, Araújo } \\
\quad \text { et al (2016) }\end{array}$ & $\begin{array}{c}\text { Índice de Pobreza } \\
\text { Multidimensional baseado } \\
\text { no método de Bourguignon e } \\
\text { Chakravarty (2003). }\end{array}$ & $\begin{array}{c}\text { Alimentos e água, comunicação e } \\
\text { informação, educação, condições } \\
\text { de moradia, saúde, trabalho e } \\
\text { demografia }\end{array}$ \\
\hline Rio Grande do Sul & $\begin{array}{l}\text { Vieira, Kuhn e } \\
\text { Marin (2017) }\end{array}$ & Método Alkire-Foster (2009) & $\begin{array}{c}\text { Educação, condições } \\
\text { domiciliares, saúde e condições } \\
\text { sanitárias, renda e trabalho }\end{array}$ \\
\hline
\end{tabular}

Fonte: Elaborado pelas autoras

As dimensões e os indicadores utilizados no presente estudo e mostrada no quadro 1, foram baseados no trabalho de Vieira, Kuhn e Marin (2017) que aplicaram a metodologia AF para o estado do Rio Grande do Sul. Os principais resultados que obtiveram com a análise foi que houve uma queda da incidência de pobreza multidimensional no Rio Grande do Sul que passou de 
24,16\% para 14,71\% da amostra. Também houve uma queda na média de indicadores que os pobres multidimensionalmente encontram-se privados: de 41,71\%, em 2000, para 37,67\%. A incidência de pobreza ajustada no estado gaúcho retraiu de $10,71 \%$, em 2000, para 5,54\%, em 2010 .

\section{Quadro 1 - Dimensões de pobreza selecionadas}

\begin{tabular}{|c|c|c|c|}
\hline Dimensões & \multicolumn{2}{|l|}{ Indicadores: } & Não privado se... \\
\hline \multirow[t]{2}{*}{ Educação } & Alfabetização & $\begin{array}{l}\text { - alfabetizado; } \\
\text { - não alfabetizado. }\end{array}$ & For alfabetizado. \\
\hline & Anos de estudo & $\begin{array}{l}\text { - sem instrução ou menos de } 3 \text { anos de } \\
\text { estudo; } \\
\text { - de } 4 \text { a } 7 \text { anos; } \\
\text { - de } 8 \text { a } 10 \text { anos; } \\
\text { - de } 11 \text { a } 14 \text { anos; } 15 \text { ou mais anos de } \\
\text { estudo. }\end{array}$ & Estudou 7 anos ou mais. \\
\hline \multirow[t]{3}{*}{$\begin{array}{l}\text { Condições } \\
\text { domiciliares }\end{array}$} & $\begin{array}{l}\text { Condição de } \\
\text { ocupação do imóvel }\end{array}$ & $\begin{array}{l}\text {-próprio; } \\
\text { - alugado; } \\
\text { - cedido por empregador; } \\
\text { - cedido de outra forma; } \\
\text { - outra condição. }\end{array}$ & For próprio. \\
\hline & Energia elétrica & $\begin{array}{l}\text { - domicílio tem; } \\
\text { - domicílio não tem. }\end{array}$ & Tiver acesso no domicílio. \\
\hline & Itens domiciliares & $\begin{array}{l}\text {-rádio, geladeira, televisão e máquina } \\
\text { de lavar. }\end{array}$ & $\begin{array}{l}\text { Se tiver acesso pelo menos geladeira } \\
\text { e TV. }\end{array}$ \\
\hline \multirow[t]{5}{*}{$\begin{array}{l}\text { Saúde e condições } \\
\text { sanitárias }\end{array}$} & $\begin{array}{l}\text { Abastecimento de } \\
\text { água }\end{array}$ & $\begin{array}{l}\text { - rede geral com canalização interna; } \\
\text { - rede geral sem canalização interna; } \\
\text { - poço ou nascente com canalização } \\
\text { interna; } \\
\text { - poço ou nascente sem canalização } \\
\text { interna; } \\
\text { - outra forma. }\end{array}$ & $\begin{array}{l}\text { Tiver acesso à rede geral com } \\
\text { canalização interna. }\end{array}$ \\
\hline & Instalações sanitárias & $\begin{array}{l}\text { - não têm acesso; } \\
\text {-têm acesso a sanitário. }\end{array}$ & Tiver acesso. \\
\hline & $\begin{array}{l}\text { Tipo de escoadouro } \\
\text { das instalações } \\
\text { sanitárias }\end{array}$ & $\begin{array}{l}\text { - rede geral; } \\
\text { - fossa séptica; } \\
\text { - fossa rudimentar; } \\
\text { - outro escoadouro. }\end{array}$ & Tiver acesso à rede geral. \\
\hline & Destino do lixo & $\begin{array}{l}\text { - coletado por serviço de limpeza; } \\
\text { - coletado em caçamba de serviço de } \\
\text { limpeza; } \\
\text { - queimado; } \\
\text { - enterrado. } \\
\text { - jogado em terreno baldio; } \\
\text { - jogado em rio, lago ou mar; } \\
\text { - outro destino. }\end{array}$ & $\begin{array}{l}\text { For coletado por serviço geral ou em } \\
\text { caçamba de serviço de limpeza. }\end{array}$ \\
\hline & $\begin{array}{l}\text { Número de banheiros } \\
\text { no domicílio }\end{array}$ & $\begin{array}{l}\text { - não tem banheiro no domicílio; } \\
\text { - têm pelo menos um banheiro; }\end{array}$ & $\begin{array}{l}\text { Se tiver pelo menos um banheiro no } \\
\text { domicílio. }\end{array}$ \\
\hline \multirow[t]{2}{*}{ Renda e trabalho } & Renda domiciliar & $\begin{array}{l}\text { - R\$ 154,00/pessoa moradora no } \\
\text { domicílio (2010); } \\
\text { - 1⁄2 salário mínimo per capita3 (2000). }\end{array}$ & $\begin{array}{l}\text { Obter até pelo menos o valor } \\
\text { estabelecido para cada um dos anos. }\end{array}$ \\
\hline & Emprego & $\begin{array}{l}\text { - não; } \\
\text { - sim, tem acesso a emprego. }\end{array}$ & $\begin{array}{l}\text { Se tiver empregado na semana de } \\
\text { referência. }\end{array}$ \\
\hline
\end{tabular}

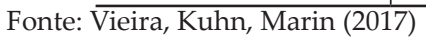

A seguir serão analisados e comentados os resultados obtidos da aplicação da metodologia AF para os municípios catarinenses em 2000 e em 2010. 


\subsection{Aplicação do Método AF para Santa Catarina (2000-2010)}

Os indicadores que apresentam as menores privações, como observado na tabela 9, em Santa Catarina são 'energia elétrica', ‘itens domiciliares' e ‘instalações sanitárias' nos dois anos de estudo. Em 2000, 1,90\% da amostra analisada não tinha acesso à energia elétrica e em 2010 esse percentual caiu para $0,24 \%$, uma redução de 1,66\%. O indicador 'itens domiciliares' obteve 2,77\% de privação em 2000, ou seja, 2,77\% dos indivíduos entrevistados em 2000 não tinham acesso à pelos menos geladeira e televisão. Em 2010, esse indicador sofreu uma redução de 2,38\% chegando a 0,24\% de privação. 'Instalações sanitárias', que indica a existência de acesso a alguma instalação sanitária para os domicílios analisados, mostrou, em 2000, que 1,75\% dos domicílios estudados em Santa Catarina eram privados nesse indicador e em 2010 esse percentual reduziu para 0,33\% dos domicílios.

Tabela 9 - Percentual de privações nos indicadores selecionados para 2000 e 2010

\begin{tabular}{l|c|c|c}
\hline Privações & 2000 & 2010 & Variação percentual \\
\hline Alfabetização & $4,79 \%$ & $3,88 \%$ & 0,91 \\
\hline Anos de estudo & $37,52 \%$ & $31,05 \%$ & 6,47 \\
\hline $\begin{array}{l}\text { Conndição de ocupação do } \\
\text { imovel }\end{array}$ & $19,33 \%$ & $22,27 \%$ & $-2,94$ \\
\hline Energia elétrica & $1,90 \%$ & $0,24 \%$ & 1,66 \\
\hline Itens domiciliares & $2,77 \%$ & $0,39 \%$ & 2,38 \\
\hline Abastecimento de água & $34,36 \%$ & $27,22 \%$ & 7,14 \\
\hline Instalações sanitárias & $1,75 \%$ & $0,33 \%$ & 1,42 \\
\hline $\begin{array}{l}\text { Tipoo de esçoadouro das instala- } \\
\text { çes sanitarias }\end{array}$ & $83,48 \%$ & $77,27 \%$ & 6,21 \\
\hline Destino do lixo & $25,19 \%$ & $12,87 \%$ & 12,32 \\
\hline $\begin{array}{l}\text { Númere de banheiros no do- } \\
\text { mićlio }\end{array}$ & $8,41 \%$ & $1,59 \%$ & 6,82 \\
\hline Renda domiciliar & $18,24 \%$ & $6,92 \%$ & 11,32 \\
\hline Emprego & $26,96 \%$ & $23,32 \%$ & 3,64 \\
\hline
\end{tabular}

Fonte: Elaborado pelas autoras

As maiores privações registradas nos dois anos de pesquisa são 'tipo de escoadouro das instalações sanitárias' que em 2000 tinha um índice de privação de 83,48\% e em 2010 obteve uma redução de 6,21 pontos percentuais com $77,27 \%$ de privação; 'anos de estudo' foi o segundo indicador com maior privação, registrando em 2000 um percentual de $37,52 \%$ e em 2010 de 31,05\%; e o terceiro indicador foi 'abastecimento de água' com um percentual de privação de $34,36 \%$ em 2000 e de $27,22 \%$ em 2010, uma redução de 7,14. A maior variação percentual positiva, isto é, o indicador que teve a maior redução de privação foi ‘destino do lixo' que em 2000 registrava um percentual de $25,19 \%$ e em 2010 de $12,87 \%$, uma variação percentual de 12,32. 'Condição de ocupação do imóvel' foi o único indicador que teve uma variação percentual negativa, ou seja, piorou ao longo da década analisada: em 2000 marcava uma porcentagem de 19,33\% de privação e em 2010 aumentou 2,94 pontos percentuais, chegando a 22, 27\% em 2010.

A Incidência de Pobreza (H) em Santa Catarina para o ano de 2000, como mostra a figura 2, indica que no geral os municípios que apresentam maior índice se encontram nas Mesorregiões Oeste, Serrana e parte das Mesorregiões Norte e do Vale do Itajaí. Já os munícipios com menores índices se situam no litoral catarinense, inclui, as Mesorregiões da Grande Florianópolis, do Sul e partes do Norte e do Vale do Itajaí. Bandeirante, Bela Vista do Toldo, Chapadão do Lageado, São Bernardino e Santa Terezinha do Progresso são os municípios com maior incidência de pobreza em 2000, possuem índices iguais a 85,86\%, $84,21 \%, 83,64 \%, 82,34 \%$ e $80 \%$ respectivamente. Os municípios com menor incidência são Balneário Camboriú com índice de 3,65\%, São José com 4,86\%, Florianópolis com 5,18\%, Criciúma com 5, 51\% e Itajaí com 6\%. No estado como um todo, $26,66 \%$ da amostra é considerada multidimensionalmente pobre. 
Figura 2 - Incidência de Pobreza (H) em 2000 e 2010
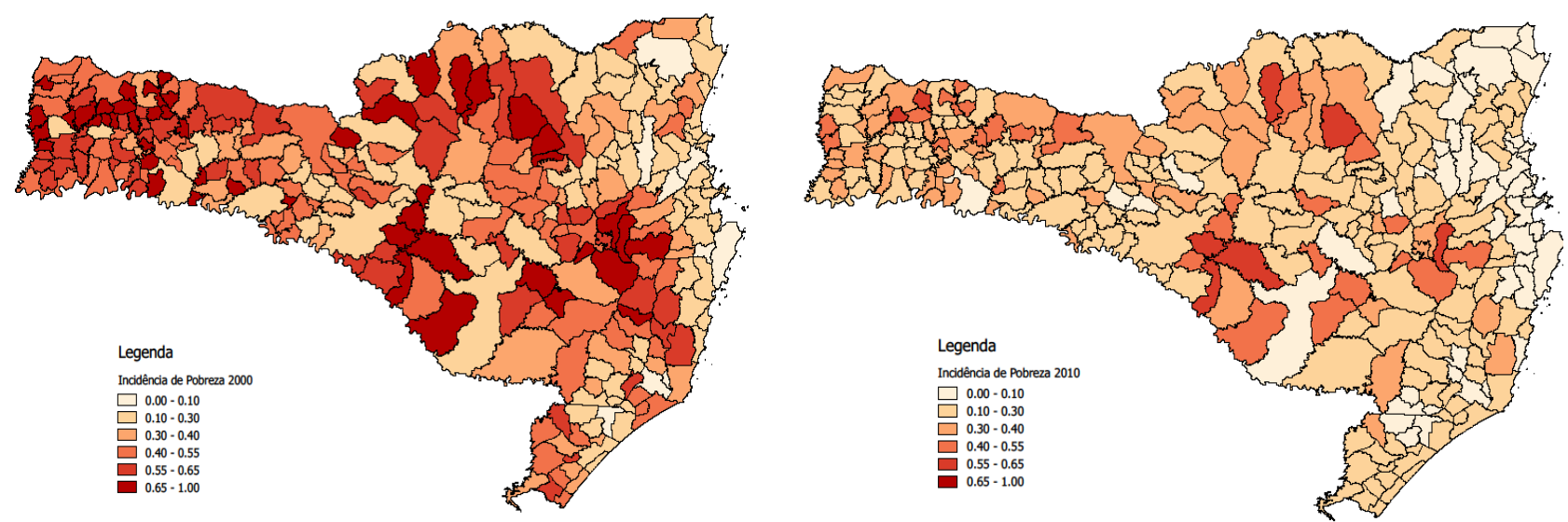

Fonte: Elaborado pelas autoras.

Já em 2010, a incidência de pobreza diminuiu, passou de 26,66\% para 15,07\%. E, assim como ocorreu em 2000, os munícipios com maior incidência de pobreza se concentram nas Mesorregiões Oeste, Serrana e parte da Norte. Os municípios localizados na costa catarinense são os que apresentam menor índice. São José do Cerrito, Bela Vista do Toldo, Santa Terezinha do Progresso, São Bernardino e Cerro Negro são os municípios verificados com maior incidência de pobreza. Seus índices são, respectivamente, 64,37\%, 64,36\%, 61,97\%, 61,42\% e 59,46\%. Balneário Camboriú, São José, Criciúma, Florianópolis e Joinville apresentam menor incidência de pobreza para o ano de 2010 com índices de 1,68\%,2,11\%,2,34\%, 2, 46\% e 2,90\%, respectivamente.

Comparando os municípios que possuem as maiores incidências registradas tanto em 2000 quanto em 2010, tem-se Bela Vista do Toldo, que teve uma redução de incidência de pobreza de 19,85\%, Santa Terezinha do Progresso com uma redução de 18.03 pontos percentuais e São Bernardino com uma diminuição de 20,92\%. Fazendo essa mesma comparação, mas observando os municípios com as menores incidências nos dois anos tem-se que Balneário Camboriú teve uma redução 1,97\%, São José almejou redução de 2.75 pontos percentuais, Florianópolis mostrou redução de 2,72\% e Criciúma contou com diminuição de 3,17\%.

Figura 3 - Hiato de Pobreza Média (A) em 2000 e 2010
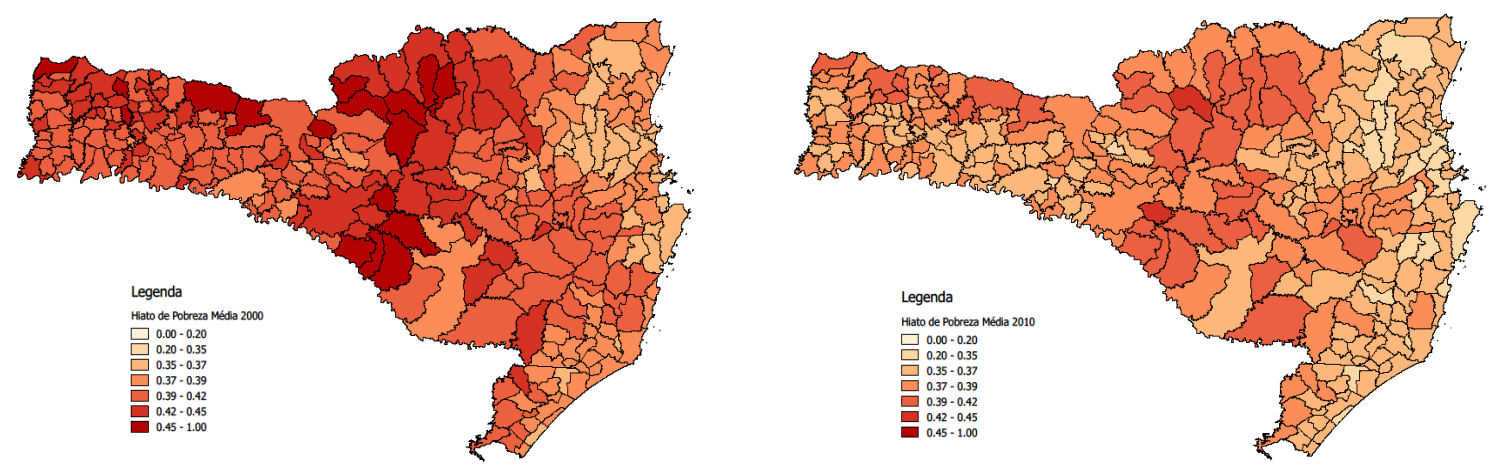

Fonte: Elaborado pelas autoras.

No que se refere ao Hiato de Pobreza Média (A) em 2000, os indivíduos considerados pobres no estado catarinense eram privados, em média, em 40,40\% dos indicadores. Os municípios com maiores privações, como é possível perceber na figura 3, são Cerro Negro com um índice de 50,49\%, Calmon com 49,93\%, Passos Maia com 49,87\%, Timbó Grande com 48,73\% e Matos Costa com 48,52\%. Já os municípios com menores índices e, portanto, com menores privações de acordo com os indicadores são Timbó, Guabiruba, Blumenau, Schroeder e Criciúma com 35,15\%, 35,45\%, 35,50\%, 35,55\% e 35,58\%, respectivamente.

Em comparação com o ano de 2010, o Hiato de Pobreza Média passou de 40,40\% para 37,34\%, uma diminuição de 3,06\%. Os municípios mais vulneráveis, isto é, que apresentam os maiores índice são Vargem, Timbó Grande, Cerro Negro, São José do Cerrito e Santa Cecília com 42,65\%, 42,03\%, 41,63\%, 41,15\% e 41,14\%, respectivamente. Presidente Castello Branco, Ascurra, Balneário Arroio do Silva, Itajaí e Timbó são os municípios com menores intensidades de pobreza e apresentam índices de 33,97\%, 34,11\%, 34,27\%, 34,35\% e 34,35\%, respectivamente. Em comparação com os valores observados de 2000, Cerro Negro mostrou uma redução de 8,86\% e Timbó Grande alcançou redução de 6,7\%. Nos municípios com menor intensidade dos dois anos estudados, tem-se Timbó que teve uma redução de apenas $0,8 \%$. 
A Incidência Ajustada $\left(\mathrm{M}_{0}\right)$ para o ano de 2000, mostra que a intensidade de pobreza em Santa Catarina de $10,77 \%$. A Incidência Ajustada revela a pobreza multidimensional ajustada a sua intensidade ou, em outras palavras, quanto mais indicadores os indivíduos pobres se revelam privados maior o indicador $\mathrm{M}_{0}$ (VIEIRA, KUHN e MARIN, 2017, p.288). Seguindo o mesmo exemplo da Incidência de Pobreza (H) e do Hiato de Pobreza Média (A), os municípios em situação mais crítica se encontram nas Mesorregiões Oeste e Serrana, engloba partes das Mesorregiões Norte e do Vale do Itajaí. Os municípios com a maior Incidência Ajustada para 2000 são Bela Vista do Toldo, Cerro Negro, Bandeirante, São Bernardino e São José do Cerrito com os respectivos índices, 39,69\%, 38,18\%, 38,16\%, 37,47\% e 36,44\%. Já os municípios com a menor Incidência Ajustada são Balneário Camboriú, São José, Florianópolis, Criciúma e Itajaí com os seguintes percentuais, $1,36 \%, 1,75 \%, 1,86 \%, 1,96 \%$ e $2,16 \%$, respectivamente.

\section{Figura 4 - Incidência Ajustada (M_0) em 2000}
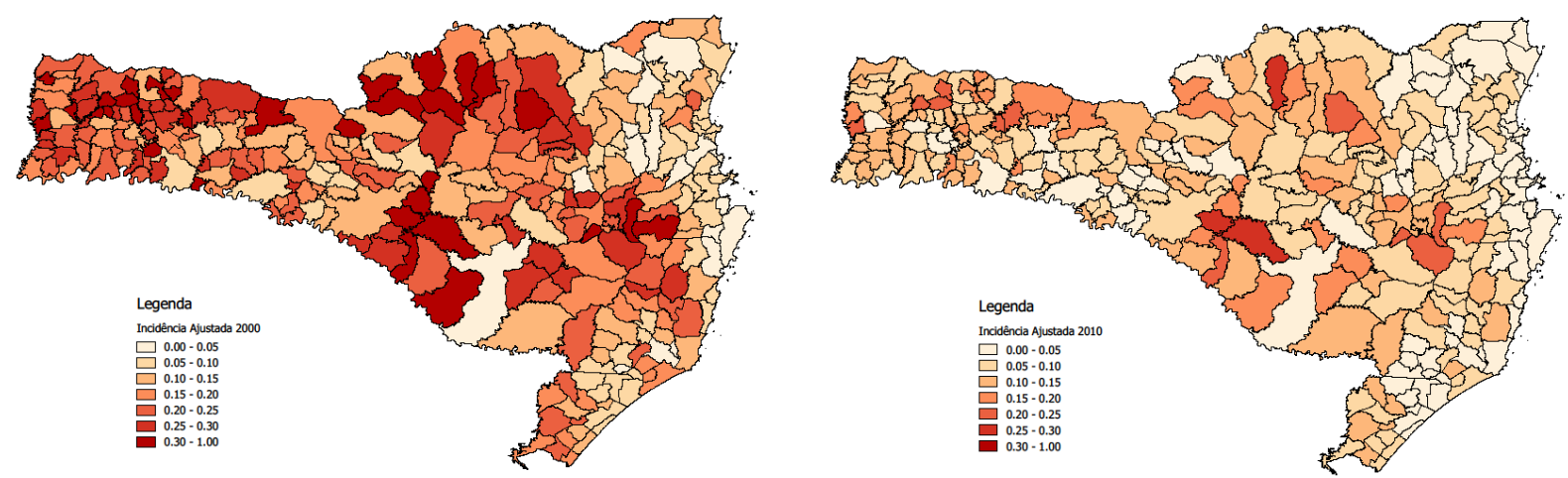

Fonte: Elaborado pelas autoras

Para o ano de 2010, a Incidência Ajustada para o estado caiu de 10,77\% em 2000 para 5,63\%, uma redução de 5,14\%. Como mostra a figura 4, as Mesorregiões com a maior Incidência Ajustada continuam as mesmas do ano de 2000, assim como, as Mesorregiões com a menor incidência. Os municípios de São José do Cerrito, Bela Vista do Toldo, Vargem, Cerro Negro e Santa Terezinha do Progresso são os que apresentam a maior incidência com índices de 26,49\%, 25,55\%, 25,22\%, 24,75\% e 24,74\%, respectivamente. Os municípios com menor incidência são Balneário Camboriú com $0,58 \%$, São José com $0,74 \%$, Criciúma com $0,81 \%$, Florianópolis com 0,85\% e Joinville com 1,01\%.

Tabela 10 - Municípios de Santa Catarina com a maior Incidência de Pobreza Ajustada (M) para 2000 e 2010

\begin{tabular}{|c|c|c|c|c|c|c|c|}
\hline \multicolumn{4}{|l|}{2000} & \multicolumn{4}{|l|}{2010} \\
\hline \multirow{2}{*}{ Santa Catarina } & $\mathrm{H}$ & $\mathrm{A}$ & $\mathrm{M}_{0}$ & \multirow{2}{*}{ Santa Catarina } & $\mathrm{H}$ & A & $\mathrm{M}_{0}$ \\
\hline & 0,2666 & 0,4040 & 0,1077 & & 0,1507 & 0,3734 & 0,0562 \\
\hline Bela Vista do Toldo & 0,8421 & 0,4714 & 0,3969 & São José do Cerrito & 0,6437 & 0,4115 & 0,2649 \\
\hline Cerro Negro & 0,7562 & 0,5049 & 0,3818 & Bela Vista do Toldo & 0,6436 & 0,3970 & 0,2555 \\
\hline Bandeirante & 0,8596 & 0,4445 & 0,3816 & Vargem & 0,5914 & 0,4265 & 0,2522 \\
\hline São Bernardino & 0,8234 & 0,4550 & 0,3747 & Cerro Negro & 0,5946 & 0,4163 & 0,2475 \\
\hline São José do Cerrito & 0,7550 & 0,4826 & 0,3644 & $\begin{array}{l}\text { Santa Terezinha do } \\
\text { Progresso }\end{array}$ & 0,6197 & 0,3992 & 0,2474 \\
\hline $\begin{array}{l}\text { Chapadão do } \\
\text { Lageado }\end{array}$ & 0,8364 & 0,4277 & 0,3577 & São Bernardino & 0,6142 & 0,4010 & 0,2463 \\
\hline Santa Terezinha & 0,7995 & 0,4469 & 0,3573 & Santa Terezinha & 0,5717 & 0,3990 & 0,2281 \\
\hline $\begin{array}{l}\text { Santa Terezinha do } \\
\text { Progresso }\end{array}$ & 0,8 & 0,4375 & 0,35 & Leoberto Leal & 0,5741 & 0,3866 & 0,2219 \\
\hline Calmon & 0,6986 & 0,4993 & 0,3489 & Entre Rios & 0,5241 & 0,4090 & 0,2144 \\
\hline Macieira & 0,7632 & 0,4532 & 0,3459 & $\begin{array}{l}\text { Chapadão do } \\
\text { Lageado }\end{array}$ & 0,5438 & 0,3906 & 0,2124 \\
\hline
\end{tabular}

Fonte: Elaborado pelas autoras.

Comparando os dois anos analisados, Bela Vista do Toldo teve redução de 14,14\%, Cerro Negro mostrou diminuição de 
12,96\% e São José do Cerrito atingiu redução de 9,95\%. Balneário Camboriú teve redução de 0.78, São José e Florianópolis registraram diminuição de $1,01 \%$ e Criciúma teve redução de $1,15 \%$. A tabela 10 destaca os dez municípios com a maior incidência ajustada de pobreza do estado de Santa Catarina nos anos de 2000 e 2010, assim como mostra a média estadual.

Tabela 11- Municípios de Santa Catarina com a menor Incidência de Pobreza Ajustada (M) para 2000 e 2010

\begin{tabular}{|c|c|c|c|c|c|c|c|}
\hline \multicolumn{4}{|l|}{2000} & \multicolumn{4}{|l|}{2010} \\
\hline \multirow{2}{*}{ Santa Catarina } & $\mathrm{H}$ & $\mathrm{A}$ & $\mathrm{M}_{0}$ & \multirow{2}{*}{ Santa Catarina } & $\mathrm{H}$ & $\mathrm{A}$ & $\mathrm{M}_{0}$ \\
\hline & 0,2666 & 0,4040 & 0,1077 & & 0,1507 & 0,3734 & 0,0562 \\
\hline Balneário Camboriú & 0,0365 & 0,3723 & 0,0136 & Balneário Camboriú & 0,0168 & 0,3439 & 0,0058 \\
\hline São José & 0,0486 & 0,3608 & 0,0175 & São José & 0,0211 & 0,3519 & 0,0074 \\
\hline Florianópolis & 0,0518 & 0,3596 & 0,0186 & Criciúma & 0,0234 & 0,3466 & 0,0081 \\
\hline Criciúma & 0,0551 & 0,3558 & 0,0196 & Florianópolis & 0,0246 & 0,3464 & 0,0085 \\
\hline Itajaí & 0,0601 & 0,3596 & 0,0216 & Joinville & 0,0291 & 0,3484 & 0,0101 \\
\hline Joinville & 0,0714 & 0,3606 & 0,0257 & Itajaí & 0,0318 & 0,3435 & 0,0109 \\
\hline Blumenau & 0,0735 & 0,3550 & 0,0261 & Capivari de Baixo & 0,0379 & 0,3480 & 0,0132 \\
\hline Brusque & 0,0756 & 0,3594 & 0,0272 & Blumenau & 0,0385 & 0,3447 & 0,0133 \\
\hline Capivari de Baixo & 0,0923 & 0,3644 & 0,0336 & Jaraguá do Sul & 0,0428 & 0,3482 & 0,0149 \\
\hline Tubarão & 0,0963 & 0,3709 & 0,0357 & Indaial & 0,0509 & 0,3476 & 0,0177 \\
\hline
\end{tabular}

Fonte: Elaborado pelas autoras.

Os municípios com as maiores incidências ajustadas se mantem os mesmos em 2000 e 2010, com exceção de Bandeirante, Calmon e Macieira que constam entre os dez de 2000, mas não de 2010 e Vargem, Leoberto Leal e Entre Rios que estão entre os dez de 2010, mas não de 2000. Em 2010, Bandeirante era o décimo terceiro município com a maior incidência ajustada de Santa Catarina, com um percentual de 20,12\%, Calmon o trigésimo quarto registrando um índice de 15,96\% e Macieira o quadragésimo sexto com 14,44\%. Já em 2000, Vargem era o décimo sétimo município com a maior incidência ajustada tendo registrado um percentual de 32,60\%, Leoberto Leal foi o trigésimo primeiro com 30,23\% e Entre Rios estava na vigésima nona posição com uma porcentagem de 30,49\%.

É possível observar com a tabela 11, que exibe os dez municípios catarinenses com a menor incidência ajustada de pobreza nos anos de 2000 e 2010, que Balneário Camboriú, São José, Florianópolis, Criciúma, Itajaí, Joinville, Capivari de Baixo e Blumenau permanecem com melhores índices relacionados à incidência ajustada. As mudanças se encontram em Brusque, que em 2000 era o oitavo município catarinense com a menor incidência ajustada e que em 2010 era o décimo quinto com um percentual de 1,89\%, Tubarão, que em 2000 estava na décima posição e em 2010 teve uma leva caída, permanecendo na décima segunda posição com 1,81\%. Jaraguá do Sul e Indaial estavam, em 2000, na décima terceira posição com 3,83\% e na décima sexta posição com 4,30\%, respectivamente, no que se refere aos melhores índices de incidência ajustada. Em 2010 , tiveram uma melhora, como é possível de analisar na tabela 12.

\section{Considerações Finais}

De forma geral, houve uma redução da incidência de pobreza entre 2000 e 2010 nos municípios de Santa Catarina. A média estadual mostra uma diminuição de 5,14\% da incidência ajustada de pobreza, de 3,06\% do hiato médio de pobreza e $11,59 \%$ da incidência de pobreza.

Santa Catarina apresenta um padrão de privação e de não privação de pobreza. Os municípios que apresentam as maiores privações nos dois anos analisados permanecem os mesmos tais como Bela Vista do Toldo, São José do Cerrito, Santa Terezinha do Progresso. Os municípios que apresentam as menores privações também são os mesmos: Balneário Camboriú, Florianópolis, Criciúma. Isso revela uma distribuição de privação por mesorregiões. Os municípios em situação mais vulnerável se encontram, de forma geral, nas mesorregiões oeste, serrana e parte da mesorregião norte. Bela Vista do Toldo é localizado na mesorregião Norte, São José do Cerrito na mesorregião Serrana, Santa Terezinha do Progresso na mesorregião Oeste. Já os municípios com os melhores percentuais se localizam na parte leste do estado catarinense, pegando praticamente todo o litoral do estado, como foi possível observar pelos mapas, o que inclui as mesorregiões da grande Florianópolis, do Vale do Itajaí, do Sul e parte da mesorregião Norte. Balneário Camboriú é localizado na mesorregião do Vale do Itajaí, Florianópolis na Grande Florianópolis e Criciúma na mesorregião Sul.

Uma revelação importante que este estudo permite auferir é que a renda monetária tem uma influência pequena na pobreza geral do estado, uma vez que os indicadores com as maiores privações são tipo de escoadouro e anos de estudo. Entre 2000 e 
2010, a renda domiciliar teve uma redução expressiva de 11,32\%, a segunda maior redução percentual perdendo apenas para o indicador destino de lixo que, como já comentado, registrou diminuição percentual de 12,32. Outro dado interessante é sobre a condição de ocupação do imóvel que registra se o imóvel ocupado pela família é próprio, alugado, cedido pelo empregador, cedido de outra forma ou outro tipo de condição. Esse indicador foi o único que apresentou uma variação percentual negativa, piorando entre os anos, de $19,33 \%$ para $22,27 \%$.

A partir disso, pode-se concluir que o entendimento da pobreza e de como ela se manifesta deve ser abordado através de um marco teórico abrangente e multidimensional. Uma vez que, como visto, focar somente na renda e ignorar outras dimensões de privação como as observadas em Santa Catarina não terá um alcance efetivo e realista do problema. Dessa forma, mostra a importância da elaboração de políticas públicas voltadas para o combate da pobreza a partir de uma abordagem multidimensional, a qual considera outras dimensões da vida das pessoas. A Abordagem das Capacitações procura compreender a pobreza como um fenômeno multifacetado que depende de fatores sociais, econômicos e pessoais. A renda é, de fato, um fator importante na elaboração de políticas públicas voltadas a erradicação da pobreza, mas, como esse estudo mostrou para o caso de Santa Catarina, há outros aspectos tão importantes quanto ou até mais relevantes que a renda como 'tipo de escoadouro', 'anos de estudo' e 'abastecimento de água' que determinam como e onde a pobreza age.

\section{REFERÊNCIAS}

ATLAS DO DESENVOLVIMENTO HUMANO DO BRASIL. Santa Catarina. Disponível em < http://www. atlasbrasil.org.br/2013/pt/perfil_uf/santa-catarina>. Acesso em: 27 nov. 2017.

ALKIRE, S.; FOSTER, J. Counting and multidimensional poverty. In: BRAUN, J. et al. The poorest and hungry: assessment, analyses, and actions. Washington: International Food Policy Research Institute, p. 77-90, 2009.

ANAND, S.; SEN, A. Concepts of Human Development and Poverty: A Multidimensional Perspective. New York: UNDP, 1997.

BRITES, M.; FERREIRA, T.; MOURA, A.; LANZA, T.; MARIN, S. Medida Multidimensional De Pobreza: Um estudo da importância das dimensões. In: SEMINÁRIO DE JOVENS PESQUISADORES EM ECONOMIA E DESENVOLVIMENTO (SJPE\&D - UFSM), v. 1, n. 1, 2013, Santa Maria. Anais eletrônicos ... Santa Maria: UFSM, 2013. Disponível em <coral.ufsm.br/seminarioeconomia/images/anais_2013/1_MEDIDA-MULTIDIMENSIONALDE-POBREZA.pdf>. Acesso em: 27 nov. 2017.

CODES, A. L. M. A Trajetória do Pensamento Científico Sobre Pobreza: Em Direção a Uma Visão Complexa. Brasília: IPEA (Textos para discussão no 1332), 2008.

CRESPO, A. P. A; GUROVITZ, E. A Pobreza como um Fenômeno Multidimensional. RAE eletrônica, v. 1, n. 2, jul./dez. 2002. Disponível em:<http://www.rae.com.br/eletronica/index. cfm?FuseAction=Artigo\&ID=1178\&Secao=PÚBLICA\&Volume=1\&Numero=2\&Ano=2002> Acesso em: 04 set. 2017.

DOTTER, C.; KLASEN, S.The Multidimensional Poverty Index: Achievements, Conceptual and Empirical Issues. UNDP Human Development Report Office (OCCASIONAL PAPER), 2014.

GIACOMELLI, G.; MARIN, S.; FEISTEL, P. Da economia tradicional do bem-estar à Abordagem das Capacitações e a importância da equidade em saúde para o desenvolvimento humano. Revista Nova Economia, v. 27, n. 1, p.89-115, 2017.

INSTITUTO BRASILEIRO DE GEOGRAFIA E ESTATÍSTICAS. Divisão Regional do Brasil em Mesorregiões e Microrregiões Geográficas. Rio de Janeiro, v. 1, 1990.

INSTITUTO BRASILEIRO DE GEOGRAFIA E ESTATÍSTICAS. Censo Demográfico - 2000: Trabalho e Rendimento: Resultados da Amostra. Disponível em < https://ww2.ibge.gov.br/home/presidencia/ noticias/26122003censotrabhtml.shtm>. Acesso em: 10 abr. 2018.

INSTITUTO DO BANCO MUNDIAL. Introduction to Poverty Analysis. Washington: World Bank, 2005. Disponível em: <siteresources.worldbank.org/PGLP/Resources/PovertyManual.pdf>. Acesso em: 09 set. 2017. 
FAHEL, M.; TELES, L.; CAMINHAS, D. PARA ALÉM DA RENDA: Uma análise da pobreza multidimensional no Brasil. Revista Brasileira de Ciências Sociais, v. 31, n. 92, p. 1-21, out. 2016.

FUNDAÇÃO DE AMPARO À PESQUISA E INOVAÇÃO DO ESTADO DE SANTA CATARINA. Mapa da Distribuição Espacial das Secretarias de Desenvolvimento Regionais (SDR) e das Mesorregiões de Santa Catarina. Disponível em < www.fapesc.sc.gov.br/files/chamada2013/Mapa_Mesorregioes_SC_IBGE.pdf>. Acesso em: 23 de fev. de 2018.

GIOVANETTI, A.; RAIHER, A. Uma análise multidimensional da pobreza dos municípios paranaenses em 2010. Revista de Estudos Sociais, v. 17, n. 33, p.228-248, 01 jun. 2015.

LEITE, A.; SILVA, A.; ARAÚJO, J.; SANTANA, G. A pobreza multidimensional no estado da Bahia diminuiu? Evidências a partir da abordagem de Bourguignon E Chakravarty. Revista de Economia Contemporânea, v. 20, n. 1, p.177-200, 2016.

LOPES, H.; MACEDO, P.; MACHADO, A. Indicador de Pobreza: aplicação de uma abordagem multidimensional ao caso brasileiro. UFMG/Cedeplar, 2003. 15p. (Texto para discussão; 223).

NOVAES, C. E. ; SANTOS, L. C. dos; PASCOALI, M. Análise econômica da mesorregião sul de Santa Catarina. Núcleo de Estudos de Economia Catarinense (NECAT), texto para discussão 006/2013.

OTTONELLI, J.; MARIANO, J. Pobreza multidimensional nos municípios da Região Nordeste. Revista Administração Pública, Rio de Janeiro, v. 48, n. 5, p. 1253-1279, set./out. 2014.

PEREIRA, P. Necessidades humanas: subsídios à crítica dos mínimos sociais. São Paulo: Cortez; 2000.

PROGRAMA DAS NAÇÕES UNIDAS PARA O DESENVOLVIMENTO, 1997. Human development report 1997: human development to eradicate poverty. New York: Oxford University Press, 1997.

PROGRAMA DAS NAÇÕES UNIDAS PARA O DESENVOLVIMENTO (PNUD). Relatório de Desenvolvimento Humano 2010: A Verdadeira Riqueza das Nações - Vias para o Desenvolvimento Humano. New York: Oxford University Press, 2010.

PROGRAMA DAS NAÇÕES UNIDAS PARA O DESENVOLVIMENTO (PNUD). Concept and Measurement of Human Development. New York: Oxford University Press, 1990.

ROCHA, S. Pobreza no Brasil: afinal, de que se trata? Rio de Janeiro: Editora FGV, 2006.

SILVA, A.; ARAÚJO, J.; CAMPELO, G.; VASCONCELOS, J; SILVA, J. Análise da pobreza multidimensional no Brasil. Revista Espacios, v. 37, n. 26, p. 17, 2016. Disponível em < http://www.repositorio.ufc.br/handle/ riufc/26860>. Acesso em: 23 out. 2017.

SEN, A. Poverty as an ordinal approach to measurement. Econometrica, v. 44, mar. 1976.

SEN, A. Equality of what? The tanner Lectures on Human Values. Stanford: Stanford University, 1979.

SEN, A. Sobre ética e economia. Companhia das Letras, 1999.

SEN, A. Desigualdade reexaminada. Rio de Janeiro: Record, 2001.

SEN, A. Desenvolvimento como liberdade. São Paulo: Companhia das Letras, 2000.

VIEIRA, C.; KUHN, D.; MARIN, S. Método Alkire-Foster: Uma Aplicação Para a Medição de Pobreza Multidimensional no Rio Grande Do Sul (2000-2010). Revista Planejamento e Políticas Públicas (PPP - Ipea), n. 48, jan./jun. 2017. 